Journal of Social Sciences and Politics

Vol. 7 No. 1 Oktober 2020

p-ISSN : 2252-4150

e-ISSN : 2716-3474

Tersedia online di http://ejurnal.stisipolcandradimuka.ac.id/index.php/JurnalPublisitas/

\title{
Model Komunikasi Pimpinan Dalam Meningkatkan Disiplin Kerja Pegawai Pada PT. Malindo Feedmill, Tbk Desa Sembawa Banyuasin
}

\author{
Ario Dendi Wijaya ${ }^{1}$ Muh.Nato Alhaq ${ }^{2}$, Asrul Nur $\operatorname{Iman}^{3}$ \\ ${ }^{1}$ Ilmu Komunikasi, STISIPOL Candradimuka \\ ${ }^{2}$ Ilmu Sosial dan Ilmu Politik, Universitas Muhamadiyah Kendari \\ ${ }^{3}$ Fakultas Ilmu Sosial dan Ilmu Politik, Universitas Pejuang Republik Indonesia \\ E-mail: ario.dendi@ stisipolcandradimuka.ac.id $^{1}$, nato.alhaq@ gmail.com ${ }^{2}$, asrulnur@gmail.com ${ }^{3}$
}

\begin{abstract}
ABSTRAK
Penelitian ini bertujuan untuk mengetahui dan mengkaji tentang Model Komunikasi pimpinan dalam meningkatkan disiplin kerja pegawai pada PT. Malindo Feedmill Tbk Desa Sembawa Kecamatan Sembawa Kabupaten Banyuasin III, dengan jumlah sampel 75 orang. Metode penelitian yang dipergunakan dalam penelitian ini adalah secara kuantitatif dengan tujuan untuk mengetahui model komunikasi pimpinan dalam meningkatkan disiplin kerja pegawai pada PT. Malindo Feedmill, Tbk dengan menggunakan rumus korelasi product moment, sedangkan instrument penelitian untuk mendapatkan data dilapangan adalah dengan menyebarkan angket yang dibuat dan dikembangkan oleh penulis sendiri berdasarkan pengembangan dari teori-teori yang relevan dengan variabel penelitian dan indikator penelitian. Berusaha memberikan gambaran tentang apa saja yang ada hubungannya dengan penelitian, kemudian menganalisanya untuk menemukan pemecahan masalah yang dihadapi. Hasil perhitungan dengan menggunakan rumus product moment untuk mengetahui model komunikasi pimpinan dalam meningkatkan disiplin kerja pegawai PT. Malindo Feedmill Tbk di Desa Sembawa Kecamatan Sembawa Kabupaten Banyuasin III adalah 0,769, sedangkan $r$ determinan $\left(r^{2}\right)$ sebesar 59,13\%, sisanya sebesar $40,87 \%$ dipengaruhi oleh faktor lain yang tidak diteliti dalam penelitian ini.
\end{abstract}

Kata kunci : Model Komunikasi Pimpinan, Disiplin Kerja, Pegawai

\section{ABSTRACT}

This study aims to see and examine the leadership communication model in improving employee work discipline at PT. Malindo Feedmill Tbk, Sembawa Village, Sembawa District, Banyuasin III Regency, with a sample size of 75 people. The research method used in this research is quantitative with the aim of knowing the leadership communication model in improving the work discipline of employees at PT. Malindo Feedmill, Tbk using the product map formula, while the research instrument for obtaining data in the field is a school questionnaire that is created and developed by the author himself based on the development of relevant theories with research variables and research indicators. Trying to provide an overview of what is there, by researching, then analyzing it to find related problems. The results of calculations using the current product formula to see the leadership communication model in improving the work discipline of employees of PT. Malindo Feedmill Tbk in Sembawa Village, Sembawa District, Banyuasin III Regency is 0.769, while the determinant $r(r 2)$ is $59.13 \%$, the remaining is $40.87 \%$; by other factors not examined in this study.

Keywords: Leadership Communication Model, Work Discipline, Employees 
etimologis, Wilbur Schram sebagaimana dikutip oleh M.O. Palapa dan Atang Syamsuddin (1995:2)-mengatakan bahwa komunikasi berasal dari bahasa Yunani, Comunicare yang berarti bersama-sama.

Secara terminologis, komunikasi merujuk pada adanya proses penyampaian suatu pernyataan oleh seseorang kepada orang lain. Dalam pengertian ini, yang terlibat dalam komunikasi adalah manusia. Merujuk pada pendapat Ruben dan Stewart (1998:16), yang dimaksud komunikasi memang adalah komunikasi manusia. Human communication is the process through which individuals -in relationships, group, organizations and societies - respond to and create messages to adapt to the environment and one another. Bahwa komunikasi manusia adalah proses yang melibatkan individu-individu dalam suatu hubungan, kelompok, organisasi dan masyarakat yang merespon dan menciptakan pesan untuk beradaptasi dengan lingkungan satu sama lain.

penelitian ini dibedakan menjadi variabel dependen dan variabel independen.

1. Variabel independen (X) merupakan variabel bebas yang nantinya akan mempengaruhi variabel dependen yaitu Komunikasi Pimpinan (X), dengan indikator:

a. Pemberian atau penyimpanan instruksi kerja (job instruction)

b. Penjelasan dari pimpinan tentang mengapa suatu tugas perlu untuk dilaksanakan (job retionnale) c. Penyampaian informasi mengenai peraturan-peraturan yang berlaku (procedures and practices)

d. Pemberian motivasi kepada pegawai untuk bekerja lebih baik.

2. Variabel dependen (Y) adalah variabel tergantung yang keberadaannya dipengaruhi variabel lainnya. Dalam penelitian ini variabel dependen adalah Disiplin Kerja Pegawai, dengan indikator:

a. Kehadiran, Seseorang dijadwalkan untuk bekerja harus hadir tepat pada waktunya tanpa alasan apapun.

b. Waktu kerja, Waktu kerja merupakan jangka waktu saat pekerja yang bersangkutan harus hadir untuk memulai pekerjaan, waktu istirahat, dan akhir pekerjaan. Mencetak jam kerja pada kartu hadir merupakan sumber data untuk mengetahui tingkat disiplin waktu karyawan.

c. Kepatuhan terhadap perintah, Kepatuhan yaitu jika seseorang melakukan apa yang dikatakan kepadanya.

d. Kepatuhan terhadap aturan, Serangkaian aturan yang dimilki perusahaan merupakan tuntutan bagi karyawan agar patuh, sehingga dapat membentuk perilaku yang memenuhi standar perusahaan.

e. Produktivitas kerja, Produktivitas kerja yaitu menghasilkan lebih banyak dan berkualitas lebih baik, dengan usaha yang sama. 
f. Pemakaian seragam, Sikap karyawan terutama lingkungan organisasi menerima seragam kerja setiap dua tahun sekali (Lijan, 2010).

\section{METODE PENELITIAN}

\section{Jenis Penelitian}

Metode penelitian menggunakan metode penelitian Kuantitatif. Penelitian ini dilakukan di Kantor PT. Malindo Feedmill Tbk Desa Sembawa Kecamatan Sembawa Kabupaten Banyuasin, yaitu penelitian yang menjelaskan hubungan kausal antara variabel-variabel melalui pengujian hipotesis (Singarimbun dan Effendi, 1989:43) yaitu menjelaskan pengaruh variabel komunikasi pimpinan terhadap disiplin kerja pegawai. Sedangkan menurut Faisal (1992) explanatory research ditujukan untuk menemukan dan mengembangkan teori sehingga hasilnya dapat menjelaskan terjadinya suatu gejala atau kenyataan sosial tertentu.

\section{Definisi Operasional Variabel}

Berkaitan dengan pendapat di atas maka dariabel yang dianalisis dalam penelitian ini dibedakan menjadi variabel dependen dan variabel independen.

1. Variabel independen $(\mathrm{X})$ merupakan variabel bebas yang nantinya akan mempengaruhi variabel dependen yaitu Komunikasi Pimpinan (Y), dengan indikator:

a. Pemberian atau penyimpanan instruksi kerja (job instruction)

b. Penjelasan dari pimpinan tentang mengapa suatu tugas perlu untuk dilaksanakan (job retionnale)

c. Penyampaian informasi mengenai peraturan-peraturan yang berlaku (procedures and practices)

d. Pemberian motivasi kepada pegawai untuk bekerja lebih baik.

2. Variabel dependen ( $\mathrm{Y}$ ) adalah variabel tergantung yang keberadaannya dipengaruhi variabel lainnya. Dalam penelitian ini variabel dependen adalah Disiplin Kerja Pegawai, dengan indikator:

a. Kehadiran

b. Waktu kerja

c. Kepatuhan terhadap perintah

d. Kepatuhan terhadap aturan

e. Produktivitas kerja,

f. Pemakaian seragam, Sikap karyawan

\section{Populasi dan Sampel}

Adapun yang menjadi Populasi dalam penelitian ini adalah seluruh pegawai PT. Malindo Feedmill Tbk Desa Sembawa Kecamatan Banyuasin yang berjumlah 75 orang. Karena semua populasi menjadi sampel dalam penelitian, maka penelitian ini disebut penelitian populasi.

\section{Teknik Pengumpulan Data}

Data yang didapat dari sumber pertama baik individu ataupun perorangan, dari Kuesioner, Wawancara, dan Observasi (Observation).

\section{Teknik Analisis Data}

Penggunaan rumus ini karena penulis ingin mengetahui korelasi 
dari kedua variabel $\mathrm{x}$ (bebas) dan variabel y (terikat). Penelitian Komunikasi mengemukakan bahwa tingkat hubungan dapat dinilai dari hasil sebagai berikut:
a. kurang dari 0,20: hubungan rendah sekali
b. 0,20-0,40: hubungan rendah tetapi pasti
c. 0,40-0,70: hubungan yang cukup berarti
d. $\quad 0,70-0,90$ : hubungan tinggi, kuat
e. lebih dari 0,90: hubungan sangat tinggi

\section{PEMBAHASAN}

\section{Deskripsi Data Variabel Komunikasi Pimpinan (X)}

Hasil jawaban responden dengan indikator: Pemberian atau penyimpanan insrruksi kerja (Job instruction), Penjelasan dari pimpinan tentang mengapa suatu tugas perlu untuk idlaksanakan (Job retionnale), Penyampaian informasi mengenai peraturan-peraturan yang berlaku (Procedures and practices), dan Pemberian motivasi kepada pegawai untuk bekerja lebih baik.

Tabel 1. Pemberian atau penyimpanan instruksi kerja (job instruction)

Sumber: Jawaban responden

Berdasarkan data tabel di atas tentang pemberian atau penyimpanan instruksi kerja menunjukkan bahwa responden yang memberikan jawaban dengan ka kategori baik sebanyak 50 orang atau $66,66 \%$ responden yang memberikan jawaban dengan kategori cukup sebanyak 20 orang atau 26,67\% sedangkan responden yang memberikan jawaban kategori kurang sebanyak 5 orang responden atau $6,67 \%$. Dapat disimpulkan bahwa dalam penyampaian instruksi kerja sudah baik sehingga dapat dipertahankan pada masa-masa yang akan datang.

Tabel 2. Penjelasan dari pimpinan tentang tugas yang harus dilaksanakan

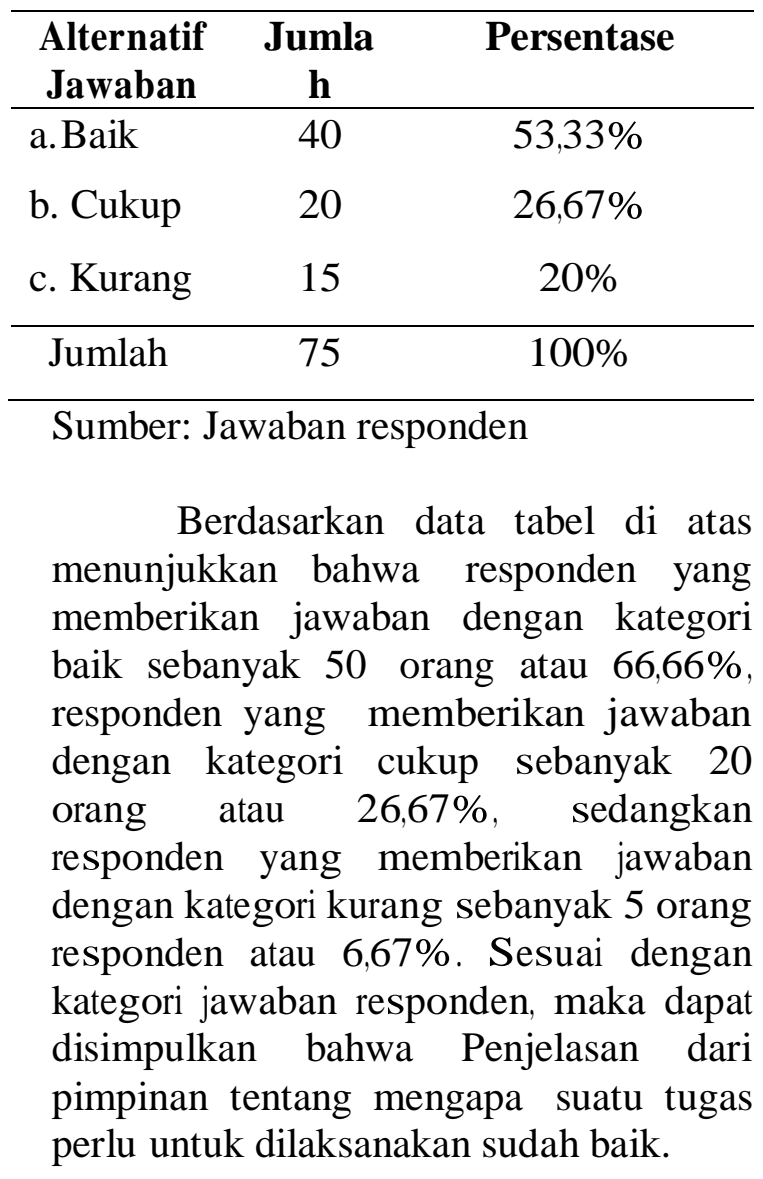

Tabel 3. Penyampaian Informasi

Alternatif
Jawaban Jumlah Persentase

$\begin{array}{lcc}\text { a. Baik } & 45 & 60 \% \\ \text { b. Cukup } & 25 & 33,33 \% \\ \text { c. Kurang } & 5 & 6,67 \%\end{array}$

\begin{tabular}{lcc}
\multicolumn{1}{c}{ Jumlah } & 75 & $100 \%$ \\
\hline $\begin{array}{l}\text { Mengenai } \\
\text { berlaku }\end{array}$ & Peraturan-Peraturan yang
\end{tabular}




\begin{tabular}{lcc}
\hline $\begin{array}{c}\text { Alternatif } \\
\text { Jawaban }\end{array}$ & Jumlah & Persentase \\
\hline a. Baik & 35 & $46,67 \%$ \\
b. Cukup & 25 & $33,33 \%$ \\
c. Kurang & 15 & $20 \%$ \\
\hline \multicolumn{1}{c}{ Jumlah } & 75 & $100 \%$
\end{tabular}

Sumber: Jawaban responden

Berdasarkan data tabel di atas menunjukkan bahwa responden yang memberikan jawaban dengan kategori baik sebanyak 40 orang atau 53,33\%, responden yang memberikan jawaban dengan kategori cukup sebanyak 20 orang atau $26,67 \%$, sedangkan responden yang memberikan jawaban dengan kategori kurang sebanyak 15 orang responden atau $20 \%$.

Tabel 4. Pemberian Motivasi kepada Pegawai untuk Bekerja Lebih Baik

\begin{tabular}{|c|c|c|}
\hline $\begin{array}{l}\text { Alternatif } \\
\text { Jawaban }\end{array}$ & Jumlah & Persentase \\
\hline a. Baik & 50 & $66,66 \%$ \\
\hline b. Cukup & 20 & $26,67 \%$ \\
\hline c. Kurang & 5 & $6,67 \%$ \\
\hline Jumlah & 75 & $100 \%$ \\
\hline
\end{tabular}

Sumber: Jawaban responden

Berdasarkan data tabel di atas menunjukkan bahwa responden yang memberikan jawaban dengan kategori baik sebanyak 45 orang atau $60 \%$ ,responden yang memberikan jawaban dengan kategori cukup sebanyak 25 orang atau 33,33\%, sedangkan responden yang memberikan jawaban dengan kategori kurang sebanyak 5 orang responden atau $6,67 \%$.

\footnotetext{
Deskripsi Data Variabel Disiplin Kerja Pegawai (Y)

Tabel 5. Kehadiran
}

\begin{tabular}{llcc}
\hline No. & $\begin{array}{c}\text { Alternatif } \\
\text { Jawaban }\end{array}$ & Jumlah & Persentase \\
\hline 1. & a. Baik & 50 & $66,66 \%$ \\
& b. Cukup & 20 & $26,67 \%$ \\
& c. Kurang & 5 & $6,67 \%$ \\
\hline & Jumlah & 75 & $100 \%$ \\
\hline
\end{tabular}

Sumber: Jawaban responden

Kehadiran adalah bagaimana seseorang dijadwalkan untuk bekerja harus hadir tepat pada waktunya tanpa alasan apapun. Dari jumlah jawaban responden didapatkan hasil sebanyak 46,67\% menjawab baik, 25 responden atau $33,33 \%$ menjawab cukup, dan sisanya sebanyak $20 \%$ menjawab kurang.

Tabel 6. Waktu Kerja

\begin{tabular}{lcc}
\hline $\begin{array}{c}\text { Alternatif } \\
\text { Jawaban }\end{array}$ & Jumlah & Persentase \\
\hline b. Baik & 30 & $40 \%$ \\
b. Cukup & 25 & $33,33 \%$ \\
c. Kurang & 20 & $26,67 \%$ \\
\hline \multicolumn{1}{c}{ Jumlah } & 75 & $100 \%$ \\
\hline
\end{tabular}

Sumber: Jawaban responden

Waktu kerja merupakan jangka waktu saat pekerja yang bersangkutan harus hadir untuk memulai pekerjaan waktu istirahat, dan akhir pekerjaan. Berdasarkan data tabel di atas menunjukkan bahwa responden yang memberikan jawaban dengan kategori baik sebanyak 30 orang atau $40 \%$, responden yang memberikan jawaban dengan kategori cukup sebanyak 25 orang atau 33,33\%, sedangkan responden yang memberikan jawaban dengan kategori kurang sebanyak 20 orang responden atau 26,67\%. Dengan 
demikian dapat disimpulkan bahwa mencetak jam kerja pada kartu hadir merupakan sumber data untuk mengetahui tingkat disiplin waktu pegawai. Dari sejumlah responden yang dimintakan jawabannya ternyata waktu kerja yang tepat hanya $40 \%$, dengan demikian masih harus ditingkatkan lagi pada masa yang akan datang.

Tabel 7. Kepatuhan terhadap Perintah

\begin{tabular}{lcc}
\hline \multicolumn{1}{c}{$\begin{array}{c}\text { Alternatif } \\
\text { Jawaban }\end{array}$} & Jumlah & Persentase \\
\hline c. Baik & 43 & $57,33 \%$ \\
b. Cukup & 20 & $26,67 \%$ \\
c. Kurang & 12 & $16 \%$ \\
\hline \multicolumn{1}{c}{ Jumlah } & 75 & $100 \%$
\end{tabular}

Sumber: Jawaban responden

Serangkaian aturan yang dimiliki organisasi merupakan tuntutan bagi pegawai agar patuh. Berdasarkan data tabel di atas menunjukkan bahwa responden yang memberikan jawaban dengan kategori baik sebanyak 43 orang atau $57,33 \%$ responden yang memberikan jawaban dengan kategori cukup sebanyak 20 orang atau $26,67 \%$ sedangkan responden yang memberikan jawaban dengan kategori kurang sebanyak 12 orang responden atau $16 \%$.

Tabel 8. Kepatuhan terhadap Aturan

\begin{tabular}{lcc}
\hline $\begin{array}{c}\text { Alternatif } \\
\text { Jawaban }\end{array}$ & Jumlah & Persentase \\
\hline d. Baik & 30 & $40 \%$ \\
b. Cukup & 25 & $33,33 \%$ \\
c. Kurang & 20 & $26,67 \%$ \\
\hline \multicolumn{1}{c}{ Jumlah } & 75 & $100 \%$
\end{tabular}

Sumber: Jawaban responden
Berdasarkan data tabel di atas tentang kepatuhan terhadap aturan menunjukkan bahwa responden yang memberikan jawaban dengan kategori baik sebanyak 30 orang atau $40 \%$, responden yang memberikan jawaban dengan kategori cukup sebanyak 25 orang atau 33,33\%, sedangkan responden yang memberikan jawaban dengan kategori kurang sebanyak 20 orang responden atau $26,67 \%$.

Tabel 9. Produktivitas Kerja

\begin{tabular}{lcc}
\hline $\begin{array}{c}\text { Alternatif } \\
\text { Jawaban }\end{array}$ & Jumlah & Persentase \\
\hline e. Baik & 30 & $40 \%$ \\
b. Cukup & 25 & $33,33 \%$ \\
c. Kurang & 20 & $26,67 \%$ \\
\hline Jumlah & 75 & $100 \%$
\end{tabular}

Sumber: Jawaban responden

Berdasarkan data tabel di atas tentang produktivitas kerja menunjukkan bahwa responden yang memberikan jawaban dengan kategori baik sebanyak 50 orang atau $66,66 \%$, responden yang memberikan jawaban dengan kategori cukup sebanyak 20 orang atau 26,67\%, sedangkan responden yang memberikan jawaban dengan kategori kurang sebanyak 5 orang responden atau $6,67 \%$.

\section{Pembahasan Hipotesis}

Menguji hipotesis yang diajukan, nilai $r$ yang diperoleh di atas dibandingkan dengan dengan nilai $r$ tabel kritik. Dengan demikian, pada taraf signifikan 0.05, $\mathrm{N}=75$ diketahui $\mathrm{r}$ tabel $=0,227$, bila $\mathrm{r}$ hitung $<\mathrm{r}$ tabel, maka hipotesis ditolak, tetapi sebaliknya bila $r$ hitung > $r$ tabel maka hipotesis diterima. 
$\mathrm{r}$ hitung $=0,769$

$r$ tabel $=0,227$

Dengan demikian hipotesis yang penulis ajukan yaitu "Diduga model komunikasi pimpinan dapat meningkatkan disiplin kerja pegawai pada PT. Malindo Feedmill Tbk Desa Sembawa Kecamatan Sembawa Kabupaten Banyuasin", dapat diterima yaitu model komunikasi pimpinan dapat peningkatan disiplin kerja pegawai PT. Malindo Feedmill Tbk Desa Sembawa Kecamatan Sembawa Kabupaten Banyuasin.

Mengetahui determinasi pengaruh antara variabel bebas terhadap variabel terikat maka dapat dilakukan perhitungan dengan mengkuadratkan koefisien determinant yang diperoleh, sebagai berikut: $\mathrm{r}=0,769$ maka diperoleh $\mathrm{r}^{2}=$ 0,5913 . Dengan demikian $\mathrm{r}$ determinant antara komunikasi pimpinan dalam meningkatkan disiplin kerja pegawai PT. Malindo Feedmill Tbk Desa Sembawa Kecamatan Sembawa Kabupaten Banyuasin, sebesar 59,13\%, sisanya sebesar $40,87 \%$ dipengaruhi oleh faktor lain yang tidak diteliti dalam penelitian ini.

\section{KESIMPULAN DAN SARAN}

\section{Kesimpulan}

Berdasarkan uraian dari bab sebelumnya, maka peneliti dapat diambil kesimpulan sebagai berikut:

1. Ada hubungan antara model komunikasi pimpinan terhadap peningkatan disiplin kerja pegawai pada PT. Malindo Feedmill Tbk sebesar 0,76. Hubungan tersebut bila dikonsultasikan dengan kriteria koefisien korelasi guiford 0,70-0,90 maka hubungannya tinggi kuat.

2. Berdasarkan hasil penelitian antara nilai variabel bebas dan nilai variabel terikat maka didapatlah nilai koefisien korelasi 0,769, dan bila kita lihat pada tabel krtitik menunjukkan angka 0,227 dengan taraf signifikan sebesar 5\%.

3. Komunikasi pimpinan berdampak positif terhadap peningkatan disiplin kerja pegawai, hal ini dapat dilihat dari jawaban responden yang sudah baik.

\section{Saran}

1. Waktu Kerja merupakan jangka waktu saat pekerja yang bersangkutan harus hadir untuk memulai pekerjaan, waktu istirahat, dan akhir pekerjaan. Berdasarkan data, ternyata waktu kerja masih kurang karena hanya $40 \%$ saja, dengan demikian masih harus ditingkatkan lagi pada masa yang akan datang.

2. Sebuah organisasi akan sebaik dengan pemimpinnya, dan pemimpin akan sebaik dengan orang-orang yang dipilihnya. Namun kenyataan pada level organisasi perusahaan swasta, khususnya pimpinan PT. Mallindo Feedmill Tbk, lebih mengedepankan pada aspek budaya dan keluarga, sehingga profesionalitas di kesampingkan. Oleh karena itu, perlu menempatkan pegawai sesuai dengan kompetensinya masing-masing.

\section{DAFTAR PUSTAKA}

[1] Lijan. 2010. Kinerja Pegawai Teori Pengkuhan dan Implikasi, Simbiosa, Jakarta 
[2] Lateiner, A.R., and Lavine, J.E, 1990, Teknik Memimpin Pegawai dan Pekerja. Terjemahan Aksara Baru, Jakarta.

[3] Pratikno, Riyono. 1995. Komunikasi Pembangunan. Penerbit Alumni. Bandung.

[4] Rahmat. 1994. Metode Penelitian Komunikasi. Remadja Karya CV

[5] A. Ali Hasymi, 1996, Intisari Manajemen, Bina Aksara, Jakarta.

[6] Moenir A.S., 1995. Pendekatan Manusiawi dan Organisasi Terhadap Pembinaan Kepegawaian.
Cetakan keenam, PT Ikrar Mandiriabadi, Jakarta.

[7] Moenir A.S., 1995, Pendekatan Manusiawi dan Organisasi Terhadap Pembinaan Kepegawaian. Cetakan keenam, PT Ikrar Mandiriabadi, Jakarta.

[8] Hadi, Sutrisno, 1997. Metodologi Research, Jilid I, Cetakan kedua puluh sembilan, Penerbit Andi, Yogyakarta.

[9] Nasir. M, 1995, Metode Penelitian. Ghalia Indonesia. 